\title{
Effect of Swastika Slot in Square Fractal Antenna
}

\author{
Manisha Narang \\ Research Scholar \\ Department of ECE, \\ PIET, Samalkha, INDIA
}

\author{
Parveen Singla \\ Assistant Professor, \\ Department of ECE, \\ PIET, Samalkha, INDIA
}

\author{
K.K. Paliwal, PhD \\ Director \& Professor \\ Department of ECE, \\ PIET, Samalkha, INDIA
}

\begin{abstract}
In the modern wireless communication systems, antennas of multiple bands, smaller size and wider bandwidth are high in demands to meet the requirement of multiple applications. This has initiated the research in new antenna fields; fractal antenna theory is one among them. Its unique properties such as selfsimilarity and space filling lead to multiband and size reduction characteristics. Due to smaller size and multiband characteristics fractal antenna has drawn the attention of researchers. Fractal antennas have more electrical length, improved SWR and impedance in a reduced physical area. The aim of this work is to design an antenna of square shape with swastika slot for multiband characteristics and efficient gain. The proposed fractal antenna has the dimensions of $22 \mathrm{~mm} \mathrm{x}$ $22 \mathrm{~mm}$. The antenna is fabricated on FR4epoxy substrate with dielectric constant $\left(\varepsilon_{\mathrm{r}}\right)=4.4$ and thickness $1.5676 \mathrm{~mm}$, which is easily available in market and cheap, thus making antenna cost effective. The structure has been designed using four swastika shapes in between two square rings on two sides. In this antenna only single iteration with the scaling factor 0.5 has been done to see the effect of iteration on the geometry. The designing and simulation of the antenna has been done using Ansoft HFSS software. The designed antenna resonates at seven different frequencies $4.9 \mathrm{GHz}, 5.8 \mathrm{GHz}, 8 \mathrm{GHz}, 13.8 \mathrm{GHz}$, $22.3 \mathrm{GHz}, 26 \mathrm{GHz}$ and $27.6 \mathrm{GHz}$. The Gains at these frequencies are $5.8099 \mathrm{dBi}, 1.6628 \mathrm{dBi},-2.0782 \mathrm{dBi}, 3.6563 \mathrm{dBi}, 4.7219 \mathrm{dBi}$, $5.2740 \mathrm{dBi}$ and $7.0985 \mathrm{dBi}$ respectively. This antenna can be used in different $\mathrm{C}$ and $\mathrm{Ku}$ band applications such as satellite and long distance telecommunication.
\end{abstract}

\section{Keywords}

Fractal antenna, SWR, Ansoft HFSS software, Swastika slot, Iteration, Reflection coefficient, Gain.

\section{INTRODUCTION}

Wireless technology has gone through different phases of development since its inception. Over these years different standards in this technology have been evolved out of the demands. Earlier it was impossible to implement long distance

communication using wired technology. So this drawback of wired technology has initiated the research for transmission over long distances and new concept of wireless communication came. The communication using electromagnetic wave has replaced wired technology to wireless technology. In modern telecommunication systems, antennas of smaller dimensions and wider bandwidth are preferred. With the evolution of antenna theory new design concepts of antenna have been introduced. By using fractal geometry multiband antenna can be constructed and this is known as "Fractal Antenna". It is more than a decade, fractal geometries are being applied in the design of passive components in the RF (radio frequency) and microwave domain. This geometry came in to its existence due to B.B. Mandelbrot in the year 1975 [11]. This intensive study was being conducted in 1970's. Later in the mid of 1990 's, it was seen that the properties of such geometry could be used to design frequency selective surface, multiband antenna and also new configurations of antenna array. Several fractal based antenna geometries have been reported in recent years $[12,13]$. In fractal antenna applications, the Minkowski loop, the Koch curve monopole, the Koch island patch, the Sierpinski carpet and the Sierpinski gasket have been reported. In particular, the Sierpinski gasket fractal monopole antenna demonstrates a $\log$ periodic resonant property. Although the fractal structure from these mathematical functions provide attractive multiband performance, it has become necessary to modify such geometry to enhance their applications. Several advances have since been made in these existing geometries, [9], [14] along with which some new geometry have come up, which are suitable for many applications where low profile, light weight, low cost, simple geometry, compatibility with integrated circuit and conformability in mounting on the host body are required. Further researches and efforts are going to advance the antenna features to meet the coming challenges.

\section{WORK METHODOLOGY}

There are several commercially available softwares which allow the simulation of antenna parameters. The work methodology starts with the study of fractal antenna. The related literature survey is done on fractal antenna. The steps taken for the antenna design are represented in the flow chart. The implementation of this project includes two main parts which are software design and hardware design. The software simulation includes the designing of new Swastika shaped fractal antenna. High frequency simulator structure (HFSS) is used for designing and simulation of the proposed antenna. The hardware design includes antenna fabrication on double sided higher radiation resistance than a similarly sized regular patch antenna. In this work, concentric ring geometry for the design of a multi-frequency fractal antenna is used, the sides of which is slotted using a swastika shape.

\subsection{Proposed Antenna Design}

This section discusses the designing of the Swastika slot square fractal antenna along with fabrication and measurement process. In general, ring antennas have narrower bandwidth and copper clad substrate (FR4 epoxy) of dielectric constant Er=4.4. The fabricated antenna is tested using vector network analyzer for the reflection constant and compared with the simulated reflection constant. 


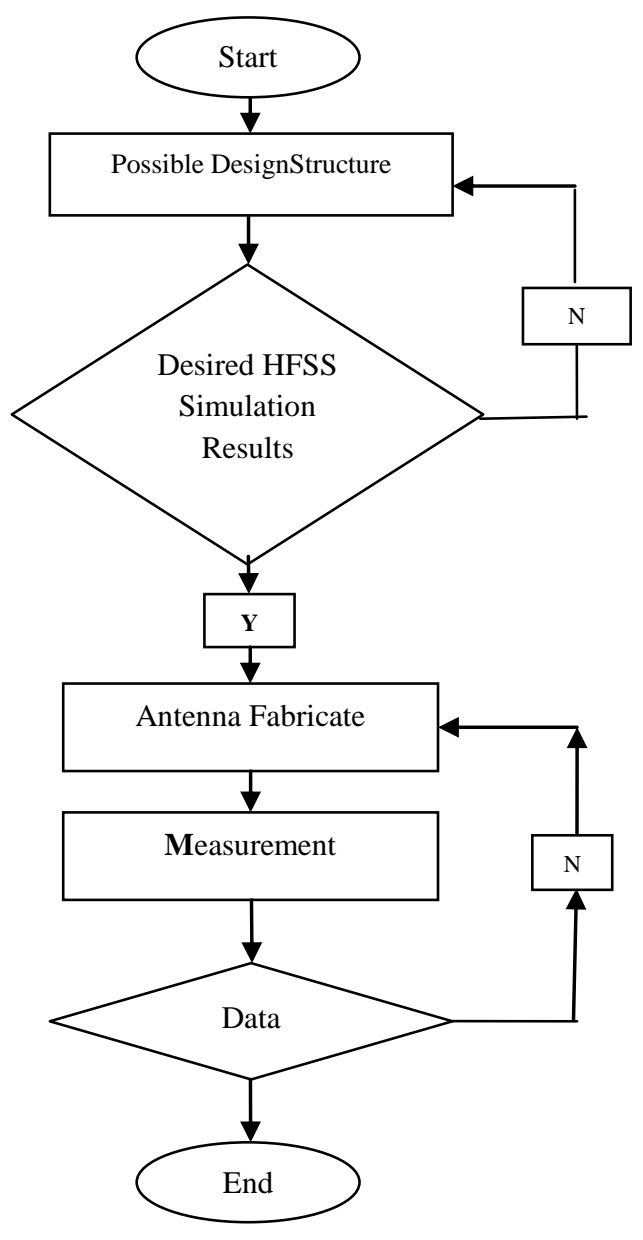

\subsubsection{Swastika slot square fractal antenna}

The fractal geometry has been designed using a Swastika shape. A square is used as an initiator to create a generator or zeroth iteration. In the generator, sides are reduced by using a Swastika shaped slot between outer square ring $(17 \mathrm{~mm} \mathrm{x}$ $0.6 \mathrm{~mm})$ and inner square ring $(12.2 \mathrm{~mm} \times 0.6 \mathrm{~mm})$. The Swastika slot is formed by cutting the four Square shapes at the two sides of a square. Figure 1 shows the design stages for the swastika shaped fractal antenna, structure in brown color implies the conducting part of antenna and grey colour shows the slots.
Initiator

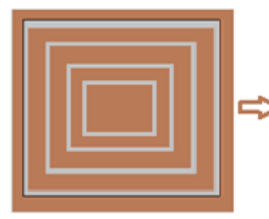

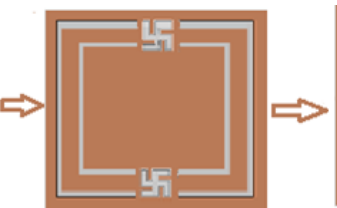

Oth iteration

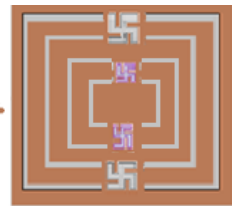

1st iteration
Figure 1: Design stages for Swastika Slot Square Fractal Antenna

\subsubsection{Square Ring Fractal Antenna}

Figure 2 shows the square ring fractal antenna. It has four square rings, outer square ring $(17 \mathrm{~mm} \times 0.6 \mathrm{~mm})$, second square ring $(12.2 \mathrm{~mm} \times 0.6 \mathrm{~mm})$, third square ring $(8.5 \mathrm{~mm} \times 0.3 \mathrm{~mm})$ and fourth square ring $(6.1 \mathrm{~mm} \times 0.3 \mathrm{~mm})$. The antenna is designed using FR-4 epoxy of dielectric constant 4.4 and height $1.56 \mathrm{~mm}$.

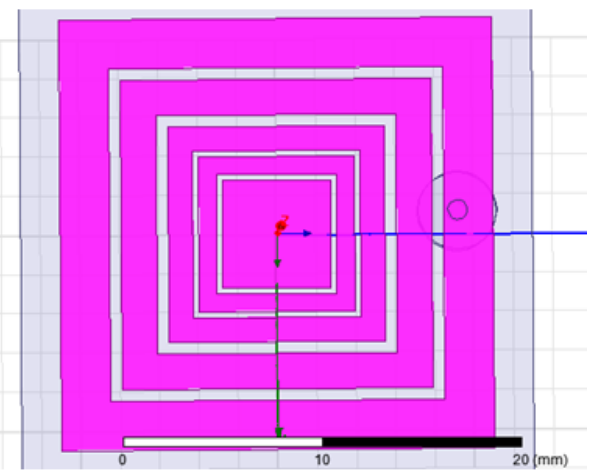

Figure 2: Square Ring Antenna

\subsection{Zeroth Iteration of Swastika slot square Fractal Antenna}

Figure 3 shows the Zeroth iteration of the proposed antenna. It has two square rings, outer square ring $(17 \mathrm{~mm} \times 0.6 \mathrm{~mm})$ and inner square ring $(12.2 \mathrm{~mm} \times 0.6 \mathrm{~mm})$, Swastika shape is kept in between these rings on four sides. The purpose of using Swastika shape is to shift the resonant frequency in the lower region. The Swastika shape is formed by cutting four Square shapes at the four sides of a square having dimensions $\mathrm{L}=3$ $\mathrm{mm}, \mathrm{W}=3 \mathrm{~mm}$. The zeroth iteration is used as the building block for the successive iterations.

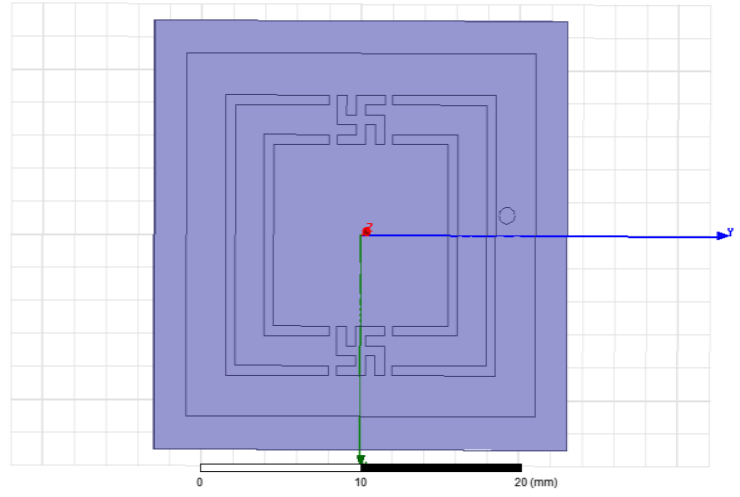

Figure 3: Zeroth iteration of the Swastika Shaped Antenna

\subsection{First Iteration of Swastika Slot Square Fractal Antenna}

Figure 4 depicts the First iteration of Swastika Slot Square fractal antenna, which is scaled down by a factor of 0.5 .

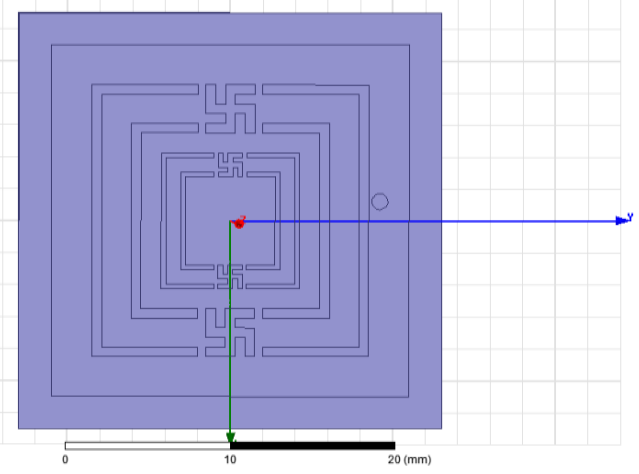

Figure 4: First iteration of antenna 


\section{RESULTS \& DISCUSSION}

The antenna of multiple frequencies is designed and simulated in HFSS version 14.0. The antenna structure is formed using square ring. The antenna design starts with specifying the materials used. To design this antenna copper is used as an antenna element and FR4 epoxy as substrate. Coaxial feed method is used to excite the antenna. Generally, antenna with high negative value of reflection coefficient and high gain is required.

\subsection{Square Ring Antenna}

To study the designed antenna, it is necessary to know the behavior of square ring and Swastikas in square rings. Square structure is an initiator in design process of the Swastika shaped antenna. There are four rings in the structure, outer first layer is scaled down by a factor of 0.5 to get the second layer and second layer is scaled down by the same to achieve next layer and so on. The overall dimensions of square ring antenna are $\mathrm{L}$ $=22 \mathrm{~mm}, \mathrm{~W}=22 \mathrm{~mm}$, designed using FR4 epoxy substrate of $\mathrm{h}=$ $1.5676 \mathrm{~mm}$ and relative permittivity $\varepsilon r=4.4$. The structure is simulated in HFSS software to study the behavior. Figure 5 depicts the same.

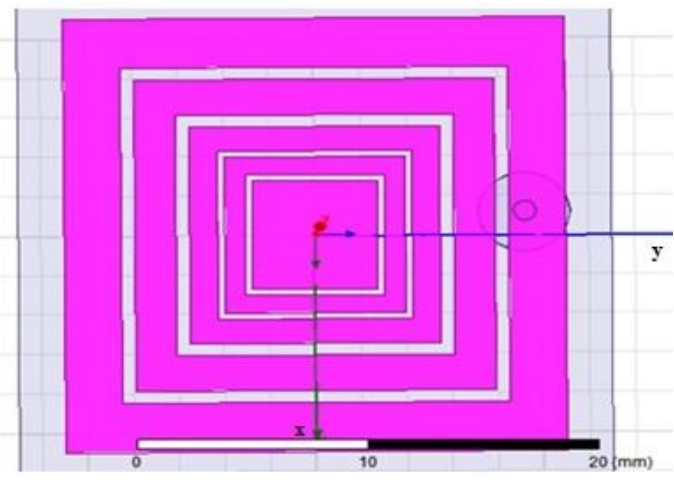

Figure 5: Square Ring Antenna

\subsection{Reflection Coefficient (S11 parameter)}

Reflection coefficient or Return loss is calculated for 0 to 20 $\mathrm{GHz}$ frequency range. Return loss is a measure of the effectiveness of power delivered from a transmission line to a load. Figure 6 depicts the S11 parameter for Square ring antenna. The antenna resonates at seven frequencies $5.1 \mathrm{GHz}$, $6.7 \mathrm{GHZ}, 7.6 \mathrm{GHz}, 11 \mathrm{GHz}, 13.3 \mathrm{GHz}, 23.6 \mathrm{GHz}$ and $27.5 \mathrm{GHz}$ having S11as $-12.108 \mathrm{dBi}, \quad-11.0317 \mathrm{dBi},-10.9925 \mathrm{dBi}$, $11.4433 \mathrm{di}, \quad-16.7933 \mathrm{dBi}, \quad-19.19 \mathrm{dBi}$ and $-23.4821 \mathrm{dBi}$ respectively.

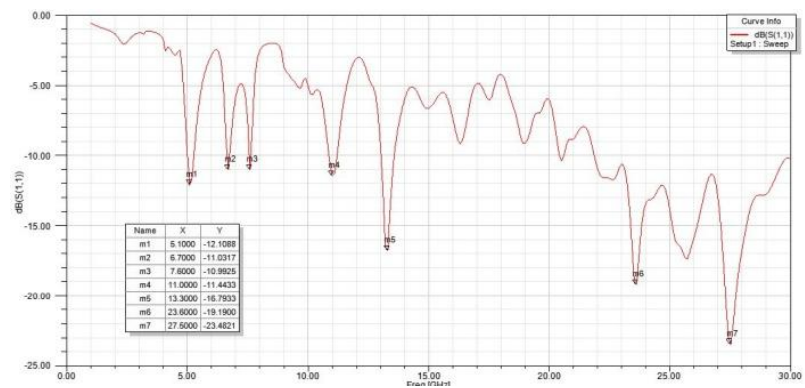

Figure 6: S11 Parameter for Square Ring Antenna

\subsection{Gain Total}

Figure 7 shows the radiation pattern of the square ring antenna The maximum gains of antenna at respective resonant frequencies are $4.9 \mathrm{dBi}, 0.4314 \mathrm{dBi}, 3.7659 \mathrm{dBi}, 1.8357 \mathrm{dBi}$, $3.5175 \mathrm{dBi}, 4.7578 \mathrm{dBi}$ and $5.9895 \mathrm{dBi}$.

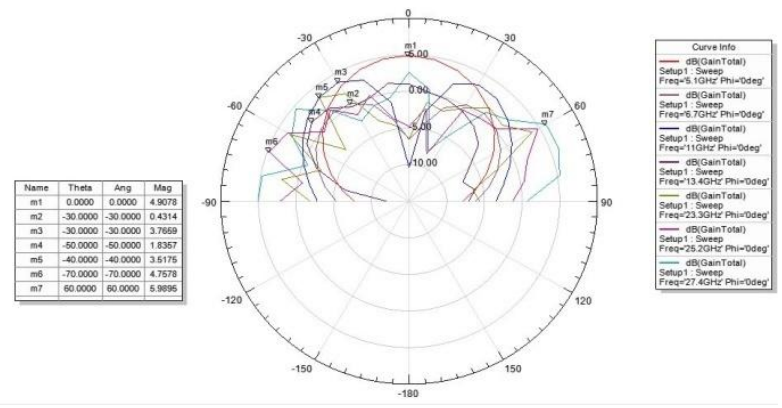

Figure 7: Gain total of first iteration for square ring antenna

\section{CONCLUSION \& FUTURE WORK}

Fractal antenna engineering is a new field of research. Research yielded a rich class of new antenna designs. The aim of this thesis is to design a new small size Swastika shaped fractal antenna of $(22 \times 22) \mathrm{mm} 2$. The proposed fractal antenna has been designed in 3D modeler window of HFSS, an FEM solver for high frequency structure. In the designed zeroth iteration structure for Swastika shapes have been used on the four sides of two square rings to shift the resonant frequencies in the lower region antenna operates in three frequencies $4.7 \mathrm{GHz}, 6.2 \mathrm{GHz}$ and $7.5 \mathrm{GHz}$. To see the effect of iterations on the designed structure, first iteration has been done. In the first iteration, the designed fractal antenna resonates at seven different frequencies $4.9 \mathrm{GHz}, 5.8 \mathrm{GHz}, 8 \mathrm{GHz}, 13.8 \mathrm{GHz}, 22.3 \mathrm{GHz}, 26 \mathrm{GHz}$ and $27.6 \mathrm{GHz}$ in two different bands of microwave spectrum i.e. $\mathrm{C}$ band(4-8 $\mathrm{GHz}$ ) and $\mathrm{Ku}$ band $(12-18 \mathrm{GHz})$. It can be used in Satellite communication and long distance telecommunication.Fractal antenna is a new field of antenna research. So there is much scope of work in this field. In the proposed work a new designed antenna has been fabricated and found the antenna's work in multiple applications. In the structure only single iteration has been done, further iterations are possible and on that basis structure of antenna can be studied further. The designed antenna can be further improved by varying various parameters like the antenna size, antenna element, feeding method and substrate.

\section{REFERENCES}

[1] Ahmed B.H., Nornikman H, Aziz, Abd M.Z.A., Othman, M.A. and Othman A.R, 2013. "Tri-band Minkowski Island Patch Antenna with Complementary Split Ring Resonator at the Ground Plane", 13th Conference on Microwave Techniques COMITE, Pardubice, Czech Republic, IEEE, pp. 46- 51.

[2] Anoop S.R., Ajayan K.K., Baiju M.R., and Krishnakumar V., 2010 "Multiband Behavioural Analysis of a Higher Order Fractal Patch Antenna" International Congress on Ultra Modern Telecommunications and Control Systems and Workshops (ICUMT), pp. 823-827.

[3] Arora, Sakshi., Gupta, Gaurav, and Gupta, Vikas, 2013. "Reduction in the Resonant Frequency of a Simple Square Patch Antenna by Loading an Asymmetrical E-Shaped Shaped in Patch", International Journal of Advanced Research in Computer Science and Software Engineering, Volume 3, Issue 7, pp. 672-678. 
[4] Azari, Abolfaz, Ismail, Alyani, Aduwati., and Hashim, Fazirulhisyam, 2013. "A New Super Wideband Fractal Monopole-Dielectric Resonator Antenna”, IEEE Antennas and Wireless Propagation Letters, Vol. 12, pp. 1014-1016.

[5] Balanis C.A., 2008. "Fundamental Parameters and Definitions for Antennas", IEEE Transactions on Antennas \& Propagations, Vol. 17, No. 3.

[6] Baliarda, Carles Puente, Romeu, Jordi., Pous, Rafael., and Cardama, Angel., 1998. "On the behaviour of the Sierpinski Multiband Fractal Antenna", IEEE Transactions on Antennas and Propagation, Vol. 46, No. 4, pp. 517524.

[7] Behera, S. K., "Novel Tuned Rectangular Patch Antenna As a Load for Phase Power Combining" Ph.D Thesis, Jadavpur University, Kolkata.

[8] Best, Steven R, 2002. "On the Significance of Self-Similar Fractal Geometry in Determining the Multiband Behavior of the Sierpinski Gasket Antenna", IEEE Antennas and Wireless Propagation Letters, Vol. 1, pp. 22-25.

[9] Borja C, Romeu, J., 2000. "Multiband Sierpinski fractal patch antenna", IEEE AP-S Intemational Symposium, IEEE, vol.3, pp.1708-1711.
[10] Cheng, Hong-Qi, Tian, Li-Bin, and Hu, Bin-Jie, 2007. "Compact Circularly Polarized Square Microstrip Fractal Antenna with Symmetrical T-slits", International Conference on Digital Object Identifier, Wireless Communications, Networking and Mobile Computing, pp. 6130616.

[11] Kumar, Alkesh., Khatri, M., and Jadhav, J.B., 2012."Teaching tools for microstrip patch antenna design", Conference on Advances in Communication and Computing, Maharashtra, India, World Journal of Science and Technology, pp. 104-107.

[12] Gianviffwb, John P., and Rahmat-Samii, Yahya., 2002. "Fractal Antennas:A Novel Antenna Miniaturization Technique and Applications" IEEE Antenna's and Propagation Magazine, Vol. 44, No. 1.

[13] Khidre, Ahmed. Lee, Kai Fang., Yang, Fan., and Eisherbeni, Ate'., 2010. "Wideband Circularly Polarized EShaped Patch Antenna for Wireless Applications," IEEE Antennas and Propagation Magazine, Vol. 52, No.5.

[14] Prasad, R.V. Harra., Purushottam, Y., Misra, V.C., and Ashok, N., 2000. "Microstrip Fractal Patch Antenna for Multiband Communication" Electronics Letters, Vol. 36, No. 14, pp. 1179-1180. 